\title{
Vigilance throughout seven days of sensory deprivation'
}

EUGENE JOHNSON III, SEWARD SMITH, AND THOMAS I. MYERS, NAVAL MEDICAL RESEARCH INSTITUTE, Bethesda, Md. 20014

Sixty volunteer Naval enlisted men participated in a study of 7-day individual isolation. Forty Ss lived in small, dark, quiet rooms with little to do (SD). The other 20 served in a live-in-the-lab control group (C) with ad lib access to lights, recreational materials, and intercom conversation with another $C S$ if mutually desired. SD Ss were significantly superior to $C S S$ in signal detection performance on an auditory vigilance task administered after 25,73 , and $145 \mathrm{~h}$ of treatment. Both within and between sessions performance decrements over time were observed, but neither of these effects were differential for the two treatment goups.

Smith, Myers, \& Murphy (1967) have recently demonstrated that Ss sensorially deprived for $72 \mathrm{~h}$ responded to infrequently and irregularly occurring $61 \mathrm{~dB}$ tones more rapidly than ambulatory control Ss tested in either a dark, quiet test room or a lighted, quiet test room. These results provide the lone example of a facilitory effect of sensory deprivation (SD) on a simple vigilance task and suggest that this type of task may lose its soporific properties in the context of the SD environment.

The present study is a further investigation of auditory vigilance performance during exposure to SD. The parameters of the task used by Smith et al (1967) were modified toward the direction of more conventional vigilance tasks, i.e., less intense signal, more trials, and longer work period. Performance was measured several times during the course of the 7-day experiment and concomitant measures of auditory threshold were made to explore the possibility of treatment effect on auditory sensitivity. A control group $(\mathrm{C})$, confined but provided with a wide variety of sensory stimulation, was employed to control for such factors as diet, activity, body position, and subjection to continual surveillance by a monitor.

\section{METHOD}

Treatment Conditions. Both SD and C Ss lived for seven days in individual sound-reducing, light-tight cubicles containing all necessary life-sustaining facilities. SD Ss received no exteroceptive stimulation other than occasional tests. C Ss, in contrast, had feedom to control room lights could utilize a variety of materials, including television, radio, tape-recorded music, books, magazines, writing paper, and playing cards, and had the freedom to converse with one other $\mathrm{C} \mathrm{S}$ via an intercom system. Ss were requested to remain on their beds except when carrying out life-sustaining activities.

Subjects. Sixty male Naval enlisted personnel were randomly selected among volunteers to participate in either the SD or C condition. All Ss were instructed that they would be serving in one of two "relaxation" conditions; no reference was made to confinement, isolation, or sensory deprivation. Forty Ss were randomly assigned to the SD condition; 20 Ss were randomly assigned to the $\mathrm{C}$ condition.

Of the 40 SD Ss, 21 completed the seven day experiment. Of the 21 completers, equipment failure resulted in the partial loss of data for five Ss. Of the $20 \mathrm{C} \mathrm{Ss}, 19$ completed the experiment. Of the 19 completers, equipment failure resulted in the partial loss of data for four Ss. One SD S was randomly eliminated to balance the $\mathbf{N}$ in the two treatment groups. Thus, complete missed signals data were available for $15 \mathrm{SD}$ Ss and $15 \mathrm{C} \mathrm{Ss}$.

Apparatus. One $\mathrm{kHz}$ tones of .10 of a sec duration at approximately $35 \mathrm{~dB}$ (re: .0002 microbar) recorded on magnetic tape provided signals for the vigilance task. Ss received the signal through a loudspeaker and responded by pulling a spring-loaded switch lever. Missed signals were recorded by means of an Esterline-Angus 20 pen event recorder. If no response occurred within a 2-sec period after signal onset, a missed signal was declared.

A Grason-Stadler Recording Attenuator, Model E326A, in conjunction with a Hewlett-Packard Audio Oscillator and calibrated headphones was used for measuring auditory thresholds.

Procedure. C Ss were informed that room lights would be turned off and that entertainment facilities would be rendered inoperable. All Ss were instructed to remain on their beds and await a task. Individual hearing threshold tests for a $1 \mathrm{kHz}$ tone were then administered (von Békésy, 1947). Next, tape-recorded instructions were played for the alerted or warm up portion of the vigilance battery ( 15 signals at $10 \mathrm{sec}$ intervals). Immediately following the alerted trials, instructions for the vigilance portion of the battery were played. This portion consisted of 60 signals ( $1 \mathrm{kHz}$ tones) during a 90-min period. Five different intersignal intervals ranging from $.5 \mathrm{~min}$ to $2.5 \mathrm{~min}$ spaced the signals. Intervals were randomized within trial blocks of 15 signals, with the restriction that each intersignal interval occur three times within a trial block. Immediately following the 60 vigilance trials, instructions were played again for a second presentation of the alerted portion of the battery. Finally, following the alerted trials, individual hearing threshold tests were administered again. Thus, the entire battery was as follows: Auditory threshold test, alerted trials, vigilance trials, alerted trials, and auditory threshold test, in that presentation order.

The entire vigilance battery was administered beginning at 9:30 AM: (a) 24 $\mathrm{h}$ prior to the beginning of treatment conditions; (b) after $25 \mathrm{~h}$ of treatment; (c) after $73 \mathrm{~h}$ of treatment; and (d) after $145 \mathrm{~h}$ of treatment. Each $\mathrm{S}$ completing the entire experiment received the vigilance battery four times, once as a pretest and three times during treatment.

\section{RESULTS}

Vigilance Performance. The primary measure of vigilance performance was the number of signals missed during 15-trial quarters. Raw missed signals data were positively skewed and within cell variances were heterogeneous. To reduce skewness and to homogenize within cell variances, a log (missed signals +1 ) transformation was performed (Winer, 1962, p.221). These transformed data were than subjected to analysis of variance.

Means of the transformed missed signals data are presented in Fig. 1. A treatment by sessions by task quarters analysis of variance revealed significant main effects of treatments $(p<.001)$. sessions $(p<.001)$ and task quarters $(p<.001)$. Since the pretest session was included in the analysis, the significant Treatment by Sessions interaction $(p<.001)$ most appropriately reflects the effects of treatment. C Ss, while not differing from SD Ss on the pretest session, missed substantially more signals on all three during-treatment sessions.

To test for changing SD vs $\mathrm{C}$ performance with treatment duration, an analysis of variance which included only the three during-treatment sessions was performed. Although a significant sessions effect $(p<.01)$ and a significant decrement effect (task quarters) $\mathbf{p}<.01)$ were found, neither sessions nor quarters interacted significantly with treatment. The treatment by sessions effect did fall at the $10 \%$ level of confidenee, however.

Alerted trials which preceded and followed the vigilance trials were subjected to analysis of variance. No effects were signilicant. An analysis which included the 15 alerted trials and the first 15 vigilance trials which immediately followed revealed that $C$ Ss suffered a significantly greater performance decline from alerted to vigilance trials than $S D$ Ss on the three during treatment sessions $(p<.03, p<.07, p<.03$, respectively).

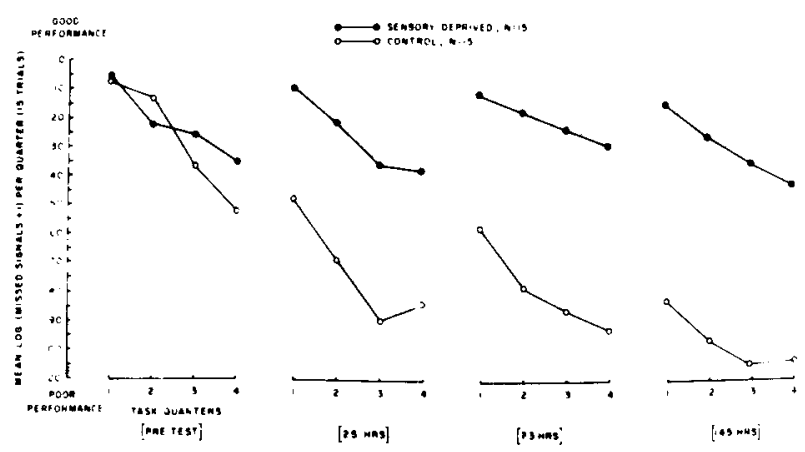

Fig. 1. Vigilance performance, mean $\log ($ missed signals +1 ) per 15-trial task quarters by treatment groups and sessions. 
Detection latency data were available for about two-thirds of Ss. Results of analyses of these data paralleled results of the analyses of missed signals data. Too few false positives occurred to permit the estimations of any signal detection theory measures of vigilance performance.

The analyses presented above were performed on transformed data. Raw group detection percentages were as follows for the pretest, 25-h, 73-h, and 145-h sessions, respectively: (a) C group $-85 \%, 52 \%, 46 \%, 29 \%$; and (b) SD group $-88 \%, 86 \%, 91 \%$, $86 \%$. The median split on missed signals summed over the three during-treatment sessions classifies 13 of 15 SD Ss as good performers but only two of $15 \mathrm{C}$ Ss as such (median test, $\mathrm{p}<$ $.001)$.

The 19 early release SD Ss who failed to complete the seven day experiment did not differ from SD Ss who did complete the experiment at any point where early release Ss contributed data.

Auditory Threshold Performance. To check for possible hearing threshold difference associated with treatment, threshold measures were made using a tone of the same frequency as the vigilance signal $(1 \mathrm{kHz})$. Measurements were taken before and after each vigilance session. Analysis of variance revealed no significant effects other than a sessions main effect. Further analysis showed the sessions main effect to be carried by the pretreatment session. The effect appeared to be a function of practice. When the pretest session was dropped from the analysis, there were no significant effects found.

\section{DISCUSSION}

These data strongly corroborate the findings of Smith et al (1967) that SD Ss are superior to nondeprived Ss in vigilance performance. This finding was upheld in the current generalized replication under substantially altered task parameters. SD Ss' superior performance was observed after $25 \mathrm{~h}$ of SD and was persistent throughout several sessions during the course of the seven day experiment.

The striking aspect of these data is that while no performance differences were evidenced during the 15 trial alerted period preceding the vigilance segment, large performance differences occurred very rapidly during the sparse stimulation of the vigilance trials (signals nine times less frequent). Performance decline after this initial rapid drop was not differential for the two treatment groups although absolute performance differences persisted.

Since pretreatment performance levels for the treatment groups were not different, any interpretation of performance on the initial during-treatment test in terms of differential expectancies as to the signal schedule (Baker, 1963) appears ruled out. However, subsequent during-treatment performance could be interpreted in terms of differential expectancies generated on the initial during-treatment test. Distractability (Broadbent, 1958) from the signal resulting from competing exteroceptive stimulation also appears to be ruled out, as both groups of Ss were tested in a dark, quiet environment. Interoceptive stimulation, which might be a potential source of distraction, is not at this time quantifiable.

The failure to find treatment group differences in auditory thresholds leads to the conclusion that the results are not a function of auditory sensitivity.
However, threshold performance may not be fully generalizable to suprathreshold performance.

Perhaps the most reasonable speculations about these results can be made in terms of stimulation-seeking and sleeping behavior of Ss. SD Ss, typically, engage in behavior which leads to increase in stimulus input. Such behavior as extreme motor restlessness, listening to inane auditory input, singing and tapping has been observed (Myers, Murphy, Smith, \& Goffard, 1966; Smith \& Myers, 1966). It is likely that even the infrequently occurring, repetitious stimulation from the vigilance task is sufficient to maintain auditory observing responses at a higher level for SD SS than for C Ss, thus increasing the probability of detecting a signal.

For $\mathrm{Ss}$ in a stimulus-reduced environment, the response in strongest competition with observing is probably sleeping. Although sleeping is common as an initial reaction to SD, it becomes less common as time in SD increases (Heron, 1957; Myers et al, 1966). For Cs recently removed from highly varied stimulation to the infrequent, repetitious stimulation of the vigilance task the likelihood of falling asleep is greater. C Ss, in fact, did report significantly greater subjective drowsiness than SD Ss during the vigilance task employed by Smith et al (1967).

Deriving little incentive value from the task stimuli and finding it difficult to remain awake when the shift, from frequent alerted trials to infrequent vigilance trials occurs, C Ss' performance abruptly declines. SD Ss, in contrast, find even repetitious exteroceptive stimulation better than none at all and, being "slept out," Ss perseverate in a state of superior vigilance.

\section{REFERENCES}

BAKER, C. H. Further toward a theory of vigilance. In D. N. Buckner \& J. J. McGrath (Eds.), Vigilance: $A$ symposium. New York: McGraw-Hill, 1963 , pp. 127-170.

BROADBENT, D. E. Perception and communication. London: Pergamon Press, 1958.

HERON, W. The pathology of boredom. Scient. American 1957, 196 (1), 52-56.

MYERS, T. I., MURPHY, D. B., SMITH, S., \& GOFFARD, S. J. Experimental studies of sensory deprivation and social isolation, Alexandria, Va.: Human Resources Research Office, June, 1966 (Tech. Rep. 66-8).

SMITH, S., MYERS, T. I., \& MURPHY, D. B. Vigilance during sensory deprivation. Percep. mot. Skills, 1967, 24, 971-976.

SMITH, S., \& MYERS, T. I. Stimulation seeking during sensory deprivation. Percep. mot. Skills, 1966, 23, 1151-1163.

von BÉKÉSY, G. A new audiometer. Acta Otolarying., Stockholm, 1947, 35, $411-422$.

WINER, B. J. Statistical principles in experimental design. New York: McGraw-Hill, 1962.

\section{NOTE}

1. From Bureau of Medicine and Surgery, Navy Department, Research Task MF022.01.03.1005. The opinions and statements contained herein are the private ones of the writers and are not to be construed as official or as reflecting the views of the Navy Department or the Naval service at large. 